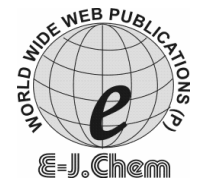

http://www.e-journals.net
ISSN: 0973-4945; CODEN ECJHAO

E-Journal of Chemistry 2009, 6(2), 361-370

\title{
Usefulness of Activated Carbon Prepared from Industrial Wastes in the Removal of Nickel from Aqueous Solution
}

\author{
R.RAJALAKSHMI, S.SUBHASHINI and P.LALITHA* \\ Department of Chemistry, Avinashilingam University for Women, \\ Coimbatore-641043, Tamilnadu, India. \\ goldenlalitha@gmail.com
}

Received 7 August 2008; Accepted 10 October 2008

\begin{abstract}
Elimination of heavy metals like nickel from waste water is an important subject in view of public health. In the present study, an attempt has been made to study the applicability of industrial by-products as potential metal adsorbents to remove nickel from aqueous solutions and polluted water. A direct proportionality between the percentage of $\mathrm{Ni}$ (II) removal and adsorbent dosage was noted. Maximum removal / recovery of nickel was achieved at $\mathrm{pH}$ range of 10-12 for all adsorbents. An optimum temperature of $40{ }^{\circ} \mathrm{C}$ for efficient removal of $\mathrm{Ni}(\mathrm{II})$ was observed. The effect of nickel adsorption was affected by salinity. The adsorption isotherm data confirmed to Freundlich and Langmuir isotherms. Conformation of data to the Lagergren's rate equation indicated first order kinetics. The suitability of the industrial by-products in the successful removal of nickel from aqueous solution is quite obvious from the study.
\end{abstract}

Keywords: Water pollution, Adsorption, Nickel pollution, Activated carbon.

\section{Introduction}

Large scale extraction of metals presents hazardous waste management problems worldwide. High concentrations of heavy metals in rivers resulting from metal extraction have adversely affected fisheries in more than $21,000 \mathrm{~km}$ of rivers ${ }^{1}$. The metals often cited for their impact on the environment are nickel, cadmium and selenium ${ }^{2}$. Elimination of heavy metals like nickel from waste water is an important subject in view of public health. According to some surveys from the public health services of different countries, a significant number of people have been exposed to the hazards of nickel in different ways ${ }^{3}$.

The widespread concern over the cumulative toxicity and environmental impact of heavy metals like nickel, chromium, cadmium etc., has led to extensive research in 
developing effective, economic, alternative technologies for the removal of these potentially damaging substances from effluents and waste water. Conventional treatment technologies like precipitation and coagulation have become less effective and more expensive. High costs, process complexity and low removal efficiency of membrane processes have limited their use in heavy metal removal ${ }^{4}$. Several workers have tried nickel adsorption using different adsorbents ${ }^{5-11}$.

Adsorption on activated carbon is a recognized method for the removal of heavy metals from waste water. The high cost of activated carbon limits its use in adsorption. In the present study, an attempt has been made for the study of industrial by-products as potential metal adsorbents to remove nickel from aqueous solutions and polluted water.

\section{Experimental}

Adsorbents

i. Lignin prepared from kraft black liquor obtained from a pulp and paper industry.

ii. Activated lignin

\section{Collection of kraft black liquor and preparation of lignin from black liquor}

Kraft black liquor was collected from a nearby pulp and paper industry where significant proportions of solid and liquid wastes are generated. The use of lignin until recent times from spent liquor was to burn in recovery boilers. This cheaply available resource can be utilized for the uptake of heavy metals.

\section{Characterization of kraft black liquor before and after lignin recovery}

Physicochemical analysis of black liquor before and after the recovery of lignin was carried out in the laboratory. The methodology for the various estimations are: iodimetric method for estimation of biological oxygen demand, reflux method for estimation of chemical oxygen demand and filtration method for estimation of total soluble salts and total dissolved solids.

\section{Preparation of lignin}

The black liquor was precipitated by titration with $1 \mathrm{~N}$ sulphuric acid at $\mathrm{pH} 2$ and filtered. The precipitate was washed with $0.01 \mathrm{~N} \mathrm{H}_{2} \mathrm{SO}_{4}$, redissolved in $1 \mathrm{~N} \mathrm{NaOH}$ and filtered to remove solids. The black solution thus obtained was again precipitated by titration with $1 \mathrm{~N}$ $\mathrm{H}_{2} \mathrm{SO}_{4}$ and finally washed with deionised water twice and dried.

\section{Preparation of activated lignin}

For every $10 \mathrm{~g}$ of lignin obtained from kraft black liquid, $5 \mathrm{~mL}$ of conc. sulphuric acid was added, washed several times with distilled water, filtered and dried at a temperature of $120{ }^{\circ} \mathrm{C}$ for $5 \mathrm{~h}$ and stored in air tight containers.

\section{Reagents}

All the reagents used were of analytical grade. To assess the performance of the adsorbents individually and to avoid interference by other elements, synthetic stock solution was prepared by dissolving $447.9 \mathrm{mg}$ of $\mathrm{NiSO}_{4} \cdot 6 \mathrm{H}_{2} \mathrm{O}$ in one litre of distilled water. The stock solution was diluted to $100 \mathrm{ppm}$.

\section{Equipments}

The BOD and COD were analyzed using a water analyzer and estimation of nickel was made through Digital Systronics colorimeter 112. 


\section{Batch experiments}

To compare and assess the adsorption capacities of the adsorbents batch experiments were carried out. Usually batch experiments are simpler and effective for evaluating the basic parameters affecting the adsorption process. Though industrial operations are not carried out batch wise, suggestions can be given for industrial applications.

\section{Procedure for optimization of adsorption parameters}

\section{Effect of adsorbent dosage}

From the synthetic stock solution (1000 ppm) of nickel sulphate, $100 \mathrm{ppm}$ solutions were prepared. $100 \mathrm{~mL}$ of the solution was equilibrated thoroughly on a horizontal bench shaker at room temperature for $90 \mathrm{~min}$ with the adsorbent at $\mathrm{pH}$ 6. The weight of the adsorbent was varied from 20 to $200 \mathrm{mg}$. After adsorption the suspensions were filtered and analysed colorimetrically at $470 \mathrm{~nm} \lambda$ by complexing with dimethyl glyoxime.

\section{Effect of $p H$}

Variation of $\mathrm{pH}$ (1 to 12) with constant dosage of adsorbents was studied. The $\mathrm{pH}$ of the solution was adjusted using diluted $\mathrm{HCl}$ and sodium hydroxide and measured using $\mathrm{pH}$ meter with glass electrode. $100 \mathrm{~mL}$ sample containing $100 \mathrm{ppm} \mathrm{Ni}$ with optimum dosage of adsorbents was shaken for $1 \mathrm{~h}$ at different $\mathrm{pH}$ conditions.

\section{Effect of time}

The effect of time was conducted by varying the contact time. $100 \mathrm{~mL}$ of $100 \mathrm{ppm}$ synthetic Ni solution containing the optimum adsorbent dosage were shaken for a time interval of 15 , 30, 45, 60, 75, 90 and $105 \mathrm{~min}$.

\section{Effect of temperature}

$100 \mathrm{~mL}$ of samples containing $100 \mathrm{ppm}$ of nickel with an optimum adsorbent dosage was kept in the temperature controlled shaker for $90 \mathrm{~min}$. The temperature was altered from $30-70{ }^{\circ} \mathrm{C}$.

\section{Effect of time at optimum temperature}

Nickel solution $(100 \mathrm{~mL})$ was shaken with optimum dosage adsorbent at optimum temperature for a time interval of 15, 30, 45 and $60 \mathrm{~min}$. The suspensions were filtered and analysed colorimetrically.

\section{Effect of $\mathrm{NaCl}$ (Salinity)}

$1 \mathrm{~g}$ of $\mathrm{NaCl}$ was dissolved in $50 \mathrm{~mL}$ of distilled water. To determine the effect of salinity on adsorption of $\mathrm{Ni}(\mathrm{II}), 100 \mathrm{~mL}$ of $100 \mathrm{ppm}$ nickel solution was mixed with the optimum dosage of the adsorbents and the contact time was fixed as 90 min and the amount of $\mathrm{NaCl}$ was varied from 1 to $5 \mathrm{~mL}$. Filtered the solution and analysed for the content of $\mathrm{Ni}$ (II).

\section{Application of kinetic studies of adsorption to nickel electroplating pollute waters}

The nickel plating waste water was diluted 10 times to get a Ni(II) concentration of 100 $\mathrm{mg} / \mathrm{litre}$ and utilized to testify the applicability of adsorption kinetic studies. For the evaluation of adsorption potentially of the adsorbents to be utilized for industrial purposes, the same experimental condition of adsorbent dosage and nickel(II) concentration were applied to the plating waste water and a contact time of $3 \mathrm{~h}$ at an alkaline $\mathrm{pH}$ (8 to 10) was maintained. The solution was then filtered and analysed for $\mathrm{Ni}(\mathrm{II})$. 


\section{Physicochemical properties of electroplating effluent}

The physicochemical properties of Ni plating water was analysed using the methodology given below. The total solids were analyzed by filtration method, turbidity by using a nephelometer, COD by reflux method, chloride content by titrimetric method, sulphate by titrimetric method, Ni by DMG method, Fe by colorimetric method and $\mathrm{Na}$, Ca by flame photometric method.

\section{Kinetic studies}

The following equations were studied to interpret the kinetics of the reaction.

i) Langmuir ii) Freundlich iii) Lagergren equation and intraparticle diffusion model for I order kinetics

\section{Results and Discussion}

Systematic laboratory batch mode studies were carried out with potential adsorbents obtained from industrial wastes like lignin and activated lignin to evaluate the optimum conditions for the removal and recovery of $\mathrm{Ni}(\mathrm{II})$ to examine their potentially for the treatment of water and waste water containing $\mathrm{Ni}(\mathrm{II})$.

\section{Characteristics of pulp and paper mill effluent (Black liquor) before and after lignin} precipitation

The characteristics of paper mill effluent collected from a nearby pulp and paper industry before and after the precipitation of lignin are presented in Table 1. The $\mathrm{pH}$ of the solution before treatment was recorded to be very high. An enormous decline in the value of $\mathrm{pH}$, BOD, COD, TSS and TDS was observed before and after precipitation. Lignin could be separated only at a very low $\mathrm{pH}$. Chlorides could not be determined at very low $\mathrm{pH}$ after treatment with sulphuric acid. Turbidity method could not be applied for the determination of sulphates since the colour of the solution before treatment was very dark.

Table 1. Characterization of black liquor before and after treatment.

\begin{tabular}{ccc}
\hline Parameters & Before treatment & After treatment \\
\hline pH & 13.87 & 1.97 \\
BOD & $56,400 \mathrm{mg} / \mathrm{L}$ & $8,100 \mathrm{mg} / \mathrm{L}$ \\
COD & $86,400 \mathrm{mg} / \mathrm{L}$ & $11,680 \mathrm{mg} / \mathrm{L}$ \\
TSS & 8,833 & 2,308 \\
TDS & $1,54,506$ & 69,536 \\
\hline
\end{tabular}

Condition: $\mathrm{m}$ 'mg' of adsorbent shaken with $100 \mathrm{~mL}$ of synthetic effluent containing 100 ppm Ni[II] ; Contact time $=90 \mathrm{~min} ; \mathrm{pH}=7$; temperature : $32 \pm 1^{\circ} \mathrm{C}$

$\mathrm{Ce}$ - concentration of $\mathrm{Ni}[\mathrm{II}]$ at equilibrium

\section{Optimization of adsorption parameters}

\section{Dependence of efficiency of $\mathrm{Ni}(\mathrm{II})$ adsorption on adsorption dosage}

Batch adsorption studies were conducted at room temperature to determine the effect of variation of adsorbent dosage and the potentially of the adsorbents on the removal of $\mathrm{Ni}$ (II) at the same sorbate concentration (100 ppm) and contact time of $90 \mathrm{~min}$, varying the dosage of adsorbents. It was noted from the results that nearly 94-97\% removal of nickel could be obtained at $200 \mathrm{mg}$ of adsorbent (Table 2). The observations could reveal a direct proportionality between the adsorbent dosage and percent of removal of nickel. The increase in the percentage of adsorption with increase in adsorbent dosage could be attributed to the increase in the surface area of the adsorbent making more sites available for adsorption. 
Table 2. Dependence of efficiency of $\mathrm{Ni}(\mathrm{II})$ adsorption on adsorption dosage.

\begin{tabular}{cccccc}
\hline Weight of & \multicolumn{2}{c}{ Lignin } & Weight of & \multicolumn{2}{c}{ Activated Lignin } \\
\cline { 2 - 3 } \cline { 5 - 6 } adsorbent, mg & Ce & Adsorption potential, \% & adsorbent,mg & Ce & Adsorption potential, \% \\
\hline 20 & 30.0 & 70.0 & 20 & 26 & 74 \\
40 & 23.0 & 77.0 & 40 & 18 & 82 \\
60 & 21.0 & 79.0 & 60 & 14 & 86 \\
80 & 17.0 & 83.0 & 80 & 11.5 & 88.5 \\
100 & 15.5 & 84.5 & 100 & 10 & 90 \\
140 & 12.0 & 88.0 & 120 & 8.5 & 91.5 \\
180 & 10.0 & 90.0 & 160 & 6 & 94 \\
200 & 6.0 & 94.0 & 200 & 3 & 97 \\
\hline
\end{tabular}

Optimization of $p H$

The $\mathrm{pH}$ of the aqueous solution is an important controlling parameter in the adsorption process and thus the role of hydrogen ion concentration was examined from solution at different $\mathrm{pH}$ ranging from 1 to 12 . The percent removal of nickel increased gradually as the $\mathrm{pH}$ value increased and attains a maximum at $\mathrm{pH}$ greater than 10 as furnished in Table 3 . At low $\mathrm{pH}$ values the surface of the sorbent would be closely associated with the hydronium ions $\left(\mathrm{H}_{3} \mathrm{O}^{+}\right)$that hinder access, by repulsion forces to the surface functional groups by the metals. At high $\mathrm{pH}$, more functional groups on the surface of the sorbent would be made available for binding with the metals. Sorption increased with increasing $\mathrm{pH}$ to the point where the metal ions precipitated which was at optimum $\mathrm{pH} 4$ to 5 in the case of electroplating waste. The results also show that maximum recovery is feasible only between $\mathrm{pH} 10$ to 12 . At higher $\mathrm{pH}$ as the concentration of $\mathrm{M}^{+}$is lowered, the surface becomes available for accumulation of $\mathrm{Ni}(\mathrm{II})$ so the adsorption may increase and the $\mathrm{pH}$ beyond 10 preclude the possibility of the metal hydroxides ${ }^{12}$ (Table 3 ).

\section{Optimization of contact time- dependence of contact time on Ni(II) adsorption}

Results furnished in the Table 4 focus a close association between the contact time and adsorption efficiency for both the adsorbents. The adsorption increased with increasing contact time and the equilibrium was attained after shaking for $90 \mathrm{~min}$. Therefore in each experiment, the shaking time was set for $90 \mathrm{~min}$.

Table 3. Optimization of $\mathrm{pH}$

\begin{tabular}{ccc}
\hline \multirow{2}{*}{$\mathrm{pH}$} & \multicolumn{2}{c}{ \% of adsorption } \\
\cline { 2 - 3 } & Lignin & Activated lignin \\
\hline 1 & 40 & 42 \\
2 & 51 & 53 \\
3 & 58 & 60 \\
4 & 63 & 65 \\
5 & 67 & 69 \\
6 & 72 & 74 \\
7 & 79 & 81 \\
8 & 85 & 87 \\
9 & 93 & 94 \\
10 & 97.5 & 97.5 \\
11 & 97.5 & 98 \\
12 & 97.5 & 98 \\
\hline
\end{tabular}

Condition: $100 \mathrm{~mL}$ of nickel solution shaken with $200 \mathrm{mg}$ of adsorbent

Contact time: $90 \mathrm{~min}$. Temperature: $32 \pm 1^{\circ} \mathrm{C}$ 
Table 4. Dependence of contact time on Ni(II) adsorption.

\begin{tabular}{ccccccccc}
\hline \multirow{2}{*}{$\begin{array}{c}\text { Contact time, } \\
\text { min }\end{array}$} & $\mathrm{Ce}$ & $\mathrm{q}$ & $\mathrm{qe}-\mathrm{q}$ & $\log (\mathrm{qe}-\mathrm{q})$ & $\mathrm{Ce}$ & $\mathrm{q}$ & $\mathrm{qe}-$ & $\log (\mathrm{qe}-\mathrm{q})$ \\
\cline { 2 - 9 } & 37 & 63 & 35.3 & 1.5477 & 32 & 68 & 30.7 & 1.4871 \\
15 & 27 & 73 & 25.3 & 1.4031 & 22 & 78 & 20.7 & 1.3159 \\
30 & 16 & 84 & 14.3 & 1.1553 & 13 & 87 & 11.7 & 1.0681 \\
45 & 3.5 & 96.5 & 1.8 & 0.2552 & 3.0 & 97 & 1.70 & 0.2304 \\
60 & 3 & 97 & 1.3 & 0.1139 & 2.5 & 97.5 & 1.20 & 0.0891 \\
75 & 1.7 & 98.3 & - & - & 1.5 & 98.7 & - & - \\
90 & &
\end{tabular}

\section{Optimization of temperature - Effect of temperature on $\mathrm{Ni}(\mathrm{II})$ adsorption}

The adsorption of $\mathrm{Ni}(\mathrm{II})$ on both the adsorbents from $30-70{ }^{0} \mathrm{C}$ has been studied and furnished in Table 5. Our findings could reveal a maximum removal of $\mathrm{Ni}(\mathrm{II})$ at $50{ }^{\circ} \mathrm{C}(323$ $\mathrm{K})$ for lignin and activated lignin. The enhanced adsorption might be due to adsorption of the ions, due to the change in size of pores and enhanced rate of intra particular diffusion.

The percent removal of $\mathrm{Ni}$ (II) increased as temperature increased up to $50{ }^{\circ} \mathrm{C}$, but at that temperature the rate of adsorption decreased. These results were supported by Pandey et al ${ }^{13}$ and several workers. This decrease in adsorption with increase in temperature greater than $50{ }^{\circ} \mathrm{C}$ might be due to the weakening of adsorptive force between active sites of the adsorbents and the adsorbate species and also between the adjacent molecules of adsorbed phase.

Table 5. Effect of temperature on $\mathrm{Ni}(\mathrm{II})$ adsorption.

\begin{tabular}{cccccccccc}
\hline Temperature & \multirow{2}{*}{$1 / \mathrm{T}$} & \multicolumn{4}{c}{ Lignin } & \multicolumn{4}{c}{ Activated lignin } \\
\cline { 3 - 10 } Kelvin & & $\mathrm{Xe}$ & $\mathrm{Ce}$ & $\mathrm{K}$ & $\mathrm{Ln} \mathrm{K}$ & $\mathrm{Xe}$ & $\mathrm{Ce}$ & $\mathrm{K}$ & $\mathrm{Ln} \mathrm{K}$ \\
\hline 303 & 0.0033 & 96.5 & 3.5 & 0.0556 & -2.8886 & 97.0 & 3.0 & 0.0584 & -2.84 \\
313 & 0.0032 & 98.2 & 1.8 & 0.0666 & -2.7077 & 98.8 & 1.2 & 0.0736 & -2.6079 \\
323 & 0.0031 & 98.8 & 1.2 & 0.1035 & -2.2678 & 99.0 & 1.0 & 0.0767 & -2.5678 \\
333 & 0.0030 & 97.7 & 2.3 & 0.0614 & -2.7894 & 98.0 & 2.0 & 0.0652 & -2.7307 \\
343 & 0.0029 & 95.5 & 4.5 & 0.0515 & -2.9666 & 96.0 & 4.0 & 0.0536 & -2.9257 \\
\hline
\end{tabular}

\section{Effect of salinity on $\mathrm{Ni}$ (II) removal}

The results of effect of salinity (Table 6) indicated a gradual decrease in the adsorption potential of $\mathrm{Ni}$ (II) by adsorbents with the increase in the amount of $\mathrm{NaCl}$.This was probably due to the relative competition between $\mathrm{Na}$ ions and metal species on the active adsorption sites of the adsorbent.

Table 6. Effect of $\mathrm{NaCl}$ on $\mathrm{Ni}$ (II) adsorption.

\begin{tabular}{ccc}
\hline $\begin{array}{c}\text { Amount of } \\
\mathrm{NaCl}, \mathrm{mL}\end{array}$ & Lignin & $\begin{array}{c}\text { Activated } \\
\text { lignin }\end{array}$ \\
\hline 0 & 96.5 & 97 \\
1 & 94.1 & 95.1 \\
3 & 90.2 & 91.3 \\
5 & 86 & 88 \\
7 & 82.3 & 83.4 \\
9 & 78.3 & 79.2 \\
\hline
\end{tabular}




\section{Kinetic modeling using lagergren equation}

Kinetics of $\mathrm{Ni}(\mathrm{II})$ adsorption follow the first order rate expression given by Lagergren

$$
\begin{aligned}
\qquad \log _{10} \mathrm{q}_{\mathrm{e}}-\mathrm{q}=\log _{10} \mathrm{q}_{\mathrm{e}}-\mathrm{k}_{\mathrm{ad}} \mathrm{t} / 2.303 \\
\text { Where, } \mathrm{K}_{\mathrm{e}}=\text { Rate constant of adsorption }(1 / \mathrm{min}) \\
\mathrm{Q}=\text { Amounts of } \mathrm{Ni}(\mathrm{II}) \text { adsorbed }(\mathrm{mg} / \mathrm{L}) \text { of adsorbent at time } \mathrm{t}(\mathrm{min}) \\
\mathrm{q}_{\mathrm{e}}=\text { Amount of } \mathrm{Ni} \text { (II) adsorbed at equilibrium time }
\end{aligned}
$$

The linear plots of $\log \mathrm{q}_{\mathrm{e}} \mathrm{q} V s \mathrm{t}$ studied at different concentrations show the applicability of above equation. The $\mathrm{K}_{\mathrm{ads}}$ and $\mathrm{K}_{\text {des }}$ values were calculated from the slopes of the linear plots (Table 7). The concentration of Ni(II) generally did not have any significant effect on the rate constants of adsorption.

\section{Weber and morris approach for intra particle diffusion}

A plot of the mass of solute adsorbed $V s$ square root of contact time gives a functional relationship commonly to describe intraparticle transport. If the controlling mechanism for adsorption is intraparticle diffusion, then linearity of the plot is achieved. The adsorption data was tested in the following equation to ascertain the role of pore diffusion.

$$
\begin{aligned}
\Delta \mathrm{q} & =\mathrm{K} x \mathrm{t}^{\mathrm{n}} \\
\log \Delta \mathrm{q} & =\log \mathrm{K}+\mathrm{n} \log \mathrm{t}
\end{aligned}
$$

Where $\Delta \mathrm{q}$ is the percentage removal, $\mathrm{t}$ is the agitation time and $\mathrm{k}$ is constant.

The plots of Ni(II) adsorbed Vs square root of time over a wide range of contact period were linear for both the adsorbents used indicating that controlling step is intra particle diffusion.

According to Weber and Morris, a value of $n=0.5$ implies pore diffusion to be the rate controlled step. If the analytical data permit the calculation of a linear regression line according to the equation, this can be taken as an indication that the implied boundary conditions are fulfilled and that the kinetics of $\mathrm{Ni}(\mathrm{II})$ adsorption are controlled by diffusion. The slopes of such regression lines yield relative rates for diffusion controlled metal adsorption. Here the value of $n>0.5$ indicated that the process is purely pore diffusion controlled (Table 7).

\section{Adsorption isotherms}

Adsorption isotherms provide design data for adsorption system. Adsorption isotherm test is one of the important tests in selecting a particular type of carbon for water, waste water and industrial treatment systems. A relationship between mass of adsorbate adsorbed per unit weight of adsorbent and liquid phase equilibrium concentration of adsorbate are represented by adsorption isotherms. The results obtained in the study of dosage variation of the adsorbent have been demonstrated in terms of Langmuir and Freundlich isotherms.

\section{Freundlich adsorption isotherm}

The Freundlich adsorption isotherm is used to quantify the equilibrium relationship between the amount of nickel (impurity) adsorbed on the carbon and the impurity concentration remaining in the solution. The equilibrium data obtained at different adsorbent dosage can be explained on the basis of Freundlich adsorption isotherm.

$$
\mathrm{x} / \mathrm{m}=\mathrm{K}_{\mathrm{t}} \cdot \mathrm{C}_{\mathrm{e}}^{1 / \mathrm{n}} \text {. }
$$

$\mathrm{x} / \mathrm{m}$ is the amount of $\mathrm{Ni}(\mathrm{II})$ adsorbed on unit weight of adsorbent in equilibrium. Ce is the equilibrium concentration of solute in aqueous solution. It can also be given in the form 


$$
\log \mathrm{x} / \mathrm{m}=\log \mathrm{K}+1 / \mathrm{n} \log \mathrm{C}_{\mathrm{e}}
$$

Freundlich parameters $\mathrm{k}$ and $1 / \mathrm{n}$ are indicators of adsorption capacity and intensity respectively. Slopes, intercepts and $\mathrm{k}$ values are displayed in Table (Table 7). The value of correlation co-efficient that was used as a main criterion for judging the fitness of the adsorption data showed. The straight line obtained in Freundlich model indicated that the average energy of adsorption decreased with increasing adsorption density. Since $1 / \mathrm{n}$ is less than 1, it indicated favourable adsorption. Mc Kay et al. (1998) observed that the value of ' $n$ ' between 1-10 represented efficient adsorption. Our experimental results were in accordance with the investigator for the adsorbent lignin.

Table 7. Interpretation of data in terms of equations.

\begin{tabular}{|c|c|c|}
\hline Equation & Lignin & Activated lignin \\
\hline Lagergren Kinetic Modelling Rate Constants & -0.0614 & -0.0599 \\
\hline Values of $\mathrm{n}$ in Weber and Morris Approach $\mathrm{n}_{\mathrm{ads}}$ & -0.7560 & -0.7362 \\
\hline \multicolumn{3}{|c|}{ Freundlich adsorption isotherm } \\
\hline K & 0.1151 & 0.1219 \\
\hline $\mathrm{n}$ & 1.1973 & 0.0494 \\
\hline $1 / \mathrm{n}$ & 0.8352 & 20.2429 \\
\hline $\mathrm{r}$ & 0.8433 & 0.9470 \\
\hline \multicolumn{3}{|c|}{ Langmuir adsorption isotherm } \\
\hline Slope & 0.5665 & 0.5871 \\
\hline Intercept & 0.6184 & 0.3565 \\
\hline $\mathrm{b}$ & 10.6269 & 16.4744 \\
\hline $\mathrm{R}_{\mathrm{L}}$ & $9.401 \times 10^{-4}$ & $6.066 \times 10^{-4}$ \\
\hline $\mathrm{r}$ & 0.7952 & 0.9113 \\
\hline
\end{tabular}

\section{Langmuir adsorption isotherm}

Langmuir adsorption isotherm is based on the assumption that points of valency exist on the surface of the adsorbent and that; each of these sites is capable of adsorbing one molecule.

Thus the adsorbed layer will be one molecule thick. Further it is assumed that all the adsorption sites have equal affinities for molecules of the adsorbent and that the presence of adsorbed molecules at one site will not affect the adsorption of molecules at an adjacent site. It is given by,

$$
\begin{aligned}
& \frac{\mathrm{x}}{\mathrm{m}}=\frac{\mathrm{K}_{1}{ }^{1} \mathrm{C}_{\mathrm{e}}}{1+\mathrm{K}_{1} \mathrm{C}_{\mathrm{e}} \mathrm{q}_{\mathrm{e}}} \text { or } \frac{\mathrm{C}_{\mathrm{e}}}{\mathrm{Q}_{\mathrm{o}} \mathrm{b}}=\frac{1 \mathrm{C}_{\mathrm{e}}}{\mathrm{Q}_{\mathrm{o}}} \\
& \mathrm{Q}_{\mathrm{o}}=\text { Langmuir constant (adsorption capacity) } \\
& \mathrm{b}=\text { Langmuir constant (energy of adsorption) } \\
& \mathrm{x}=\text { Amount of Ni(II) adsorbent } \\
& \mathrm{m}=\text { Weight of adsorbent } \\
& \mathrm{C}_{\mathrm{e}}=\text { Concentration of Ni(II) at equilibrium. On rearranging } \\
& \frac{1}{\mathrm{x} / \mathrm{m}}=\frac{1}{\mathrm{~K}_{1}{ }^{1} / \mathrm{K}_{1}}+\frac{1}{\mathrm{~K}_{1}{ }^{1} \mathrm{C}_{\mathrm{e}}}
\end{aligned}
$$

The plots of $1 / \mathrm{x} / \mathrm{m} V s 1 / \mathrm{C}_{\mathrm{e}}$ is linear with slope equal to $1 / \mathrm{K}_{1}$ and intercept $1 / \mathrm{K}_{1}$. The slope, intercept and regression co-efficients were calculated from the linear regression for adsorption (Table 7) studies. The validity of the Langmuir adsorption isotherm was verified by 
linear regression co-efficients. The linear plots of $\mathrm{m} / \mathrm{x} V s \mathrm{~s} / \mathrm{C}_{\mathrm{e}}$ shows the applicability coverage of adsorbate on the surface of the adsorbent. The essential character of Langmuir isotherm can be represented in terms of dimensionless parameter, $\mathrm{R}_{\mathrm{L}}$ called as the separation factor.

$$
\mathrm{R}_{\mathrm{L}}=\frac{1}{1+\mathrm{bC}_{\mathrm{o}}}
$$

$\mathrm{C}_{\mathrm{o}}=$ Initial metal ion concentration $(\mathrm{mg} / \mathrm{l}) . \mathrm{b}=$ Langmuir Constant $(\mathrm{L} / \mathrm{mg})$

This parameter indicates the shape of isotherm

$$
\begin{array}{ll}
\mathrm{R}_{\mathrm{L}} & \text { - Type of isotherm } \\
\mathrm{R}_{\mathrm{L}}>1 & \text { - Unfavourable } \\
\mathrm{R}_{\mathrm{L}}=1 & \text { - Linear } \\
0<\mathrm{R}_{\mathrm{L}}<1 & \text { - Favourable } \\
\mathrm{R}_{\mathrm{L}}=0 & \text { - Irreversible }
\end{array}
$$

Recorded data emphasized that the type of isotherm for ads of $\mathrm{Ni}(\mathrm{II})$ using potential adsorbent was favourable $\left(0<\mathrm{R}_{\mathrm{L}}<1\right)$.

\section{Physicochemical characteristics of nickel plating industry}

For the purpose of effective discussion about physicochemical characteristics of Ni plating, the experimental data were consolidated, tabulated and analysed. Table 8 portrayed the physicochemical characteristics of the effluent before treatment with the adsorbents. The $\mathrm{pH}$ of the effluent was found to be 1.53 which was not within the tolerance limits prescribed by the Bureau of Indian Standards (5.5 - 9.0).

Randall et $a l^{14}$ suggested that heavy metal ions attach themselves to two adjacent hydroxyl groups thereby releasing two hydrogen ions into the solution. This should, theoretically lower the $\mathrm{pH}$ in the effluent solution, an effect which was observed in all column experiments. Phenolic $\mathrm{OH}$ groups and / or carboxyl groups might be the active sites responsible for the binding of heavy metals to the straw.

Tabulation revealed a higher value of Electrical Conductivity which was probably attributed to the load off cations and anions discharged in the rinse water. This trend was expressed by several workers. Effluent recorded higher levels of chlorides, and sulphates. In the electroplating industries for the purpose of anodizing operations, 30-75 $\mathrm{g}$ of chloride salts and $250 \mathrm{~g}$ of sulphate salts were added which may be the cause for higher values of chlorides and sulphates.

Table 8. Physicochemical characteristics of electroplating industry effluents

\begin{tabular}{lc}
\hline \multicolumn{1}{c}{ Parameters } & Effluent \\
\hline $\mathrm{pH}$ & 1.53 \\
Conductivity, ms/cm & 14.83 \\
Total solids, mg/L & 8650 \\
Turbidity & 1 \\
COD, mg/L & Nil \\
Chlorides, mg/L & 414 \\
Sulphate, mg/L & 4400 \\
Nickel, mg/L & 1000 \\
Fe (II), mg/L & 56 \\
Total Fe, mg/L & 157 \\
Sodium, mg/L & 250 \\
Calcium, mg/L & 50 \\
\hline
\end{tabular}


The quantity of sodium was found to be higher $(250 \mathrm{mg} / \mathrm{L})$ than the quantity of calcium $(50 \mathrm{mg} / \mathrm{l})$ in the electroplating industrial wastes. This might be due to the usage of sodium salts in the excess amounts than the amount of calcium usage. The values of total solids $(8650 \mathrm{mg} / \mathrm{L})$ and $\mathrm{Ni}(\mathrm{II})(1000 \mathrm{mg} / \mathrm{L})$ was found to be greater than the tolerance limits for total solids and $\mathrm{Ni}$ (II) in the effluent collected from electroplating industry. In the present investigation, the high nickel content of electroplating industry effluent emphasized an imminent need to remove $\mathrm{Ni}(\mathrm{II})$ present in the effluent.

\section{Conclusion}

A direct proportionality between the percentage of $\mathrm{Ni}$ (II) removal and adsorbent dosage was noted. Maximum removal / recovery of nickel was achieved at $\mathrm{pH}$ range of 10-12 for all adsorbents. An optimum temperature of $40{ }^{\circ} \mathrm{C}$ for efficient removal of $\mathrm{Ni}$ (II) was observed. The effect of nickel adsorption was affected by salinity. The adsorption isotherm data confirmed to Freundlich and Langmuir isotherms. Conformation of data to the Lagergren's rate equation indicated first order kinetics. The suitability of the industrial by-products in the successful removal of nickel from aqueous solution is quite obvious from the study.

\section{Acknowledgement}

The authors thank the concerned authorities of the Avinashilingam University for Women, Coimbatore for providing facilities to carry out this work.

\section{References}

1. Moore J N and Luoma S N, Hazardous wastes from large scale metal extraction, Environ Sci Technol., 1990, 24.

2. Peterson P J and Girling C A, Other trace metals. In: Effect of heavy metal pollution on plants. Edited by N.W. Lepp. Applied Science Publishers, London. 1981, Vol. 1. pp. 213-278.

3. WHO, Environmental health criterial, 101, Methyl mercury, 1971, Geneva.

4. Beszedits, Heavy metal removal from waste waters, Engng.Dig, 1983, March,18-25.

5. Aurora Seco, Paula Marzal, Carmen Gabaldón and José Ferrer, J Chem Technol Biotechnol., 1999, 68(1), 23 - 30.

6. Kadirvelu K, Thamaraiselvi K and Namasivayam C, Separ Purif Tech., 2001, 24, 497-505.

7. Hasar H, J Hazard Mater., 2003, 28, 97(1-3), 49-57.

8. Awasthi. M, Rai L C, Ann Microbiol., 2004, 54, 257-267.

9. Erdoğan S, Önal Y, Akmil-Başar C, Bilmez-Erdemoğlu S, Sarıcı-Özdemir C, Köseoğlu E and İçduygu G, Appl Surface Science, 2005, 15, 1324-1331.

10. Nityanandi D, Subbhuraam C V and Kadirvelu K, Environ Technol., 2006, 27(1),15-24.

11. Madhavakrishnan S, Manickavasagam K, Rasappan K, .Syed Shabudeen P S, Venkatesh R, and S. Pattabhi, E J Chem., 2008, 5(4), 761-769.

12. Rao A L, Neelam Verma and Amarjeet Kaur, Indian J Environ Health, 1990, 32(3), 280-283.

13. Pandey K K, Prasad G and Singh V N, Wallastonite Tech Bio-Tech.,1986, 34, 367-374.

14. Randall J M, Reuter J M, Waiss A C, J Appl Polyn Sci., 1974, 22:379-389. 


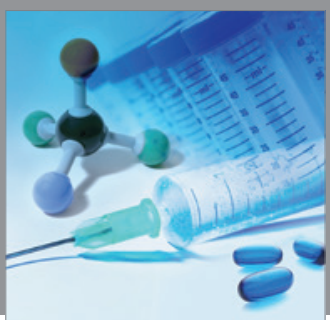

International Journal of

Medicinal Chemistry

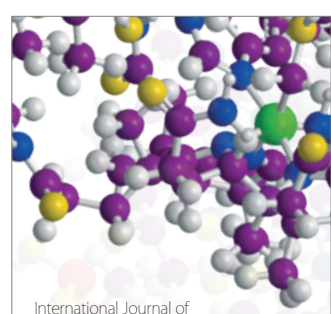

Carbohydrate Chemistry

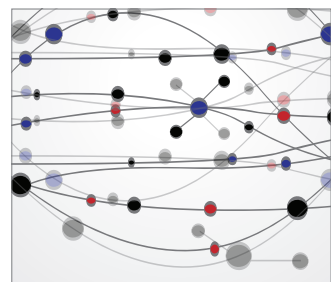

The Scientific World Journal
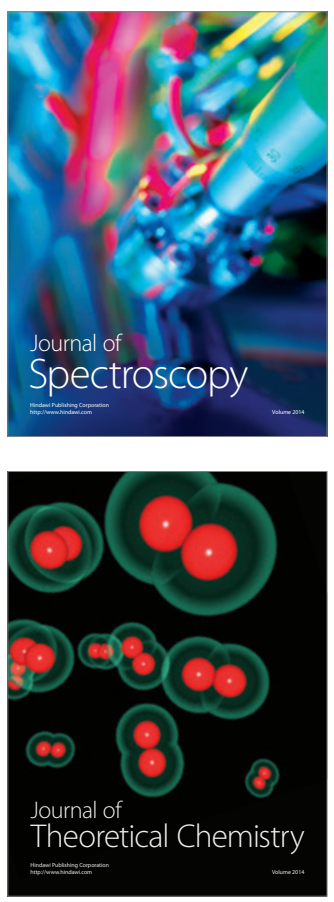
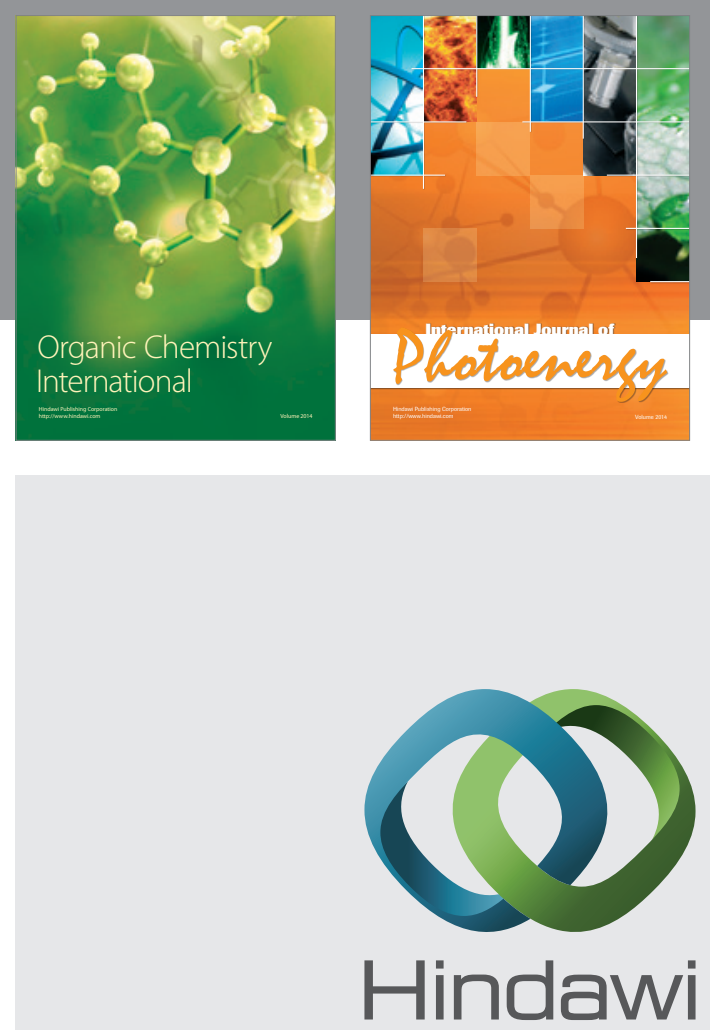

Submit your manuscripts at

http://www.hindawi.com
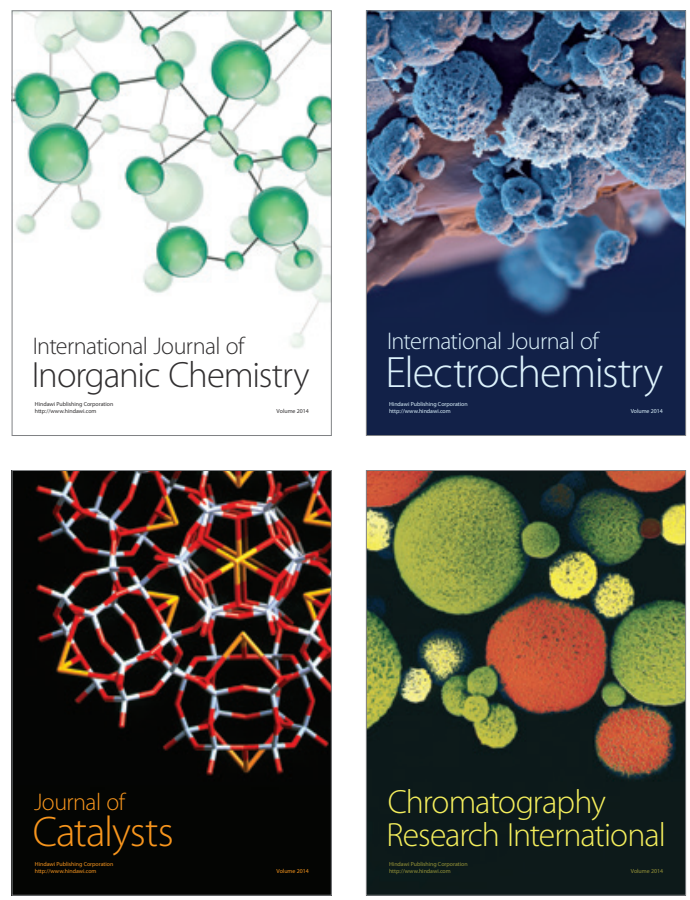
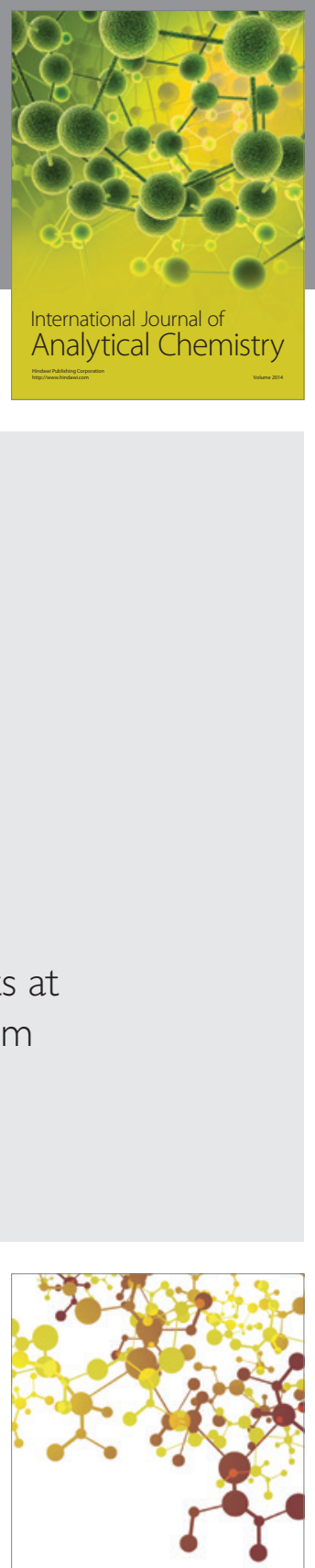

Journal of

Applied Chemistry
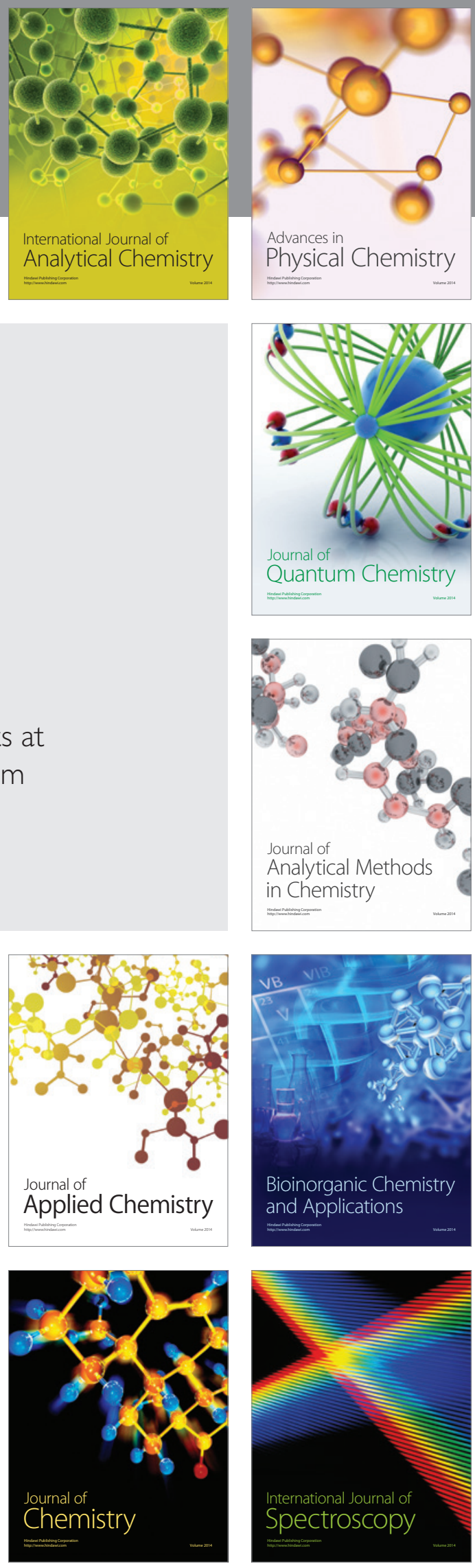